\title{
POESIA E PINTURA: RELAÇÕES POSSÍVEIS EM CONTEXTO MATO GROSSENSE
}

\author{
FORMAÇÃO DE PROFESSORES DE LITERATURA \\ Adriana Lins PRECIOSO \\ Universidade do Estado de Mato Grosso
}

\begin{abstract}
RESUMO: Do diálogo de dois projetos, o primeiro intitulado Transculturação e poéticas contemporâneas: traços identitários da cultura de Mato Grosso que teve início em 2013 e tem finalização prevista para 2016, cujo objetivo maior é estudar textos pictóricos e poéticos contemporâneos produzidos em Mato Grosso e que apresentem elementos identitários, os quais articulem o diálogo entre as artes, por meio da afirmação da memória local e preservação do cânone e, também, o segundo com o título Multiletramentos e Tecnologia: Formação e Prática Docente - MULTFOR, com o mesmo período de atuação e com o objetivo geral de analisar a relação entre formação docente, multiletramentos e o uso das tecnologias na ação pedagógica de professores da área de linguagem da Educação Básica para compreender como estes interferem nas práticas sociais; esta pesquisa socializa o trabalho relacionado junto ao PROFLETRAS da UNEMAT - Sinop, com docentes do ensino fundamental para a instrumentalização de práticas pedagógicas e alternativas teórico-metodológicas de ensino de leitura de leitura e, de forma específica, do texto poético e do texto pictórico produzidos no contexto de Mato Grosso. A base teórica para este trabalho vem com Koch e Elias (2013) e Cavalcante (2012). O poeta apresentado neste projeto é Aclyse de Mattos, com humor e concretismo. Já as pinturas estão relacionadas com a temática da mitologia judaico-cristã e a série "o cotidiano" de Mari Bueno.
\end{abstract}

PALAVRAS-CHAVE: Gêneros textuais. Poesia. Pintura.

ABSTRACT: From the dialogue of two projects, the first entitled Contemporary Transculturation and Poetics: Identity Traits of Mato Grosso Culture that began in 2013 and is scheduled to be completed in 2016, whose main objective is to study contemporary poetic and poetic texts produced in Mato Grosso and presenting Identity elements, which articulate the dialogue between the arts, through the affirmation of the local memory and preservation of the canon, and also the second one with the title Multiletramentos e Tecnologia: Formation and Teaching Practice - MULTFOR, with the same period of performance and With the general objective of analyzing the relationship between teacher training, multilearning and the use of technologies in the pedagogical action of teachers in the area of Basic Education language to understand how they interfere in social practices; This research socializes the work related to PROFLETRAS of UNEMAT Sinop, with elementary school teachers for the instrumentalisation of pedagogical practices and theoretical and methodological alternatives for teaching reading reading and, specifically, for the poetic text and pictorial text produced In the context of Mato Grosso. The theoretical basis for this work comes with Koch and Elias (2013) and Cavalcante (2012). The poet presented in this project is Aclyse de Mattos, with humor and concretism. The paintings are related to the themes of Judeo-Christian mythology and the series "o cotidiano" by Mari Bueno.

KEYWORDS: Textual genres. Poetry. Painting. 


\section{Introdução}

As concepções contemporâneas acerca do que é um texto não chegou de forma clara e objetiva aos professores das escolas públicas no Brasil, ainda há uma concepção limitada do que venha a ser um texto e quais as suas possibilidades de estrutura. Os estudos da Linguística Textual fundamentaram vários conceitos que se imbricaram ao longo dos anos e formataram um pressuposto básico do que vem a ser um texto na atualidade. De acordo com Koch e Elias (2013, p. 7):

o texto é lugar de interação de sujeitos sociais, os quais, dialogicamente, nele se constituem e são constituídos; e que, por meio de ações linguísticas e sociocognitivas, constroem objetos de discurso e propostas de sentido, ao operarem escolhas significativas entre as múltiplas formas de organização textual e as diversas possibilidades de seleção lexical que a língua lhes põe à disposição. A essa concepção subjaz, necessariamente, a ideia de que há, em todo e qualquer texto, uma gama de implícitos, dos mais variados tipos, somente detectáveis pela mobilização do contexto sociocognitivo do interior do qual se movem os atores sociais.

Para além das inovações trazidas pelas questões da interação dos sujeitos, observase a contribuição das perspectivas sociocognitivas na construção dos elementos textuais e dos seus próprios contextos, fora as escolhas lexicais, os diálogos constituídos e os implícitos que atestam a configuração do que venha a ser um texto e também garantem possíveis sentidos extraídos dele. De fato, esses avanços a respeito do que é um texto, em toda a gama de complexidade aqui apresentada, não chegou a boa parte dos professores das redes públicas em nosso país. É o que se pode apreender dos alunos do mestrado do PROFLETRAS, Mestrado Profissional em Letras, do Câmpus de Sinop-MT. Apesar da grande maioria dos professores ter mais de 10 anos de atuação profissional, logo nas primeiras aulas da disciplina obrigatória intitulada "Texto e Ensino", o conceito de texto revela-se ainda bastante limitado; os conteúdos apresentados passam a alargar esse conceito e trazer para os discentes/professores, as concepções mais atualizadas do termo.

Uma vez ampliado e atualizado o termo texto, a ação que o esquadrinha também sofre alterações, tal como propõe Koch e Elias:

Em decorrência, postula-se que a leitura de um texto exige muito mais que o simples conhecimento linguístico compartilhado pelos interlocutores: o leitor é, necessariamente, levado a mobilizar uma série de estratégias tanto de ordem linguística como de ordem cognitivodiscursiva, com o fim de levantar hipóteses, validar ou não as hipóteses formuladas, preencher as lacunas que o texto apresenta, enfim, participar, de forma ativa, da construção do sentido. Nesse processo, autor e leitor devem ser vistos como 'estrategistas' na interação pela linguagem. (2013, p. 7)

Atualmente, o entendimento de um texto compreende a noção de interação, uma vez que, ele próprio passa a ser visto como um evento, no qual os agente sociais interagem levando em consideração os contextos sociocomunicativo, histórico e cultural que o fazem produzir sentido. (CAVALCANTE, 2013, p. 19). A apreensão do contexto tanto 
do leitor quanto da produção do texto auxiliam na geração de sentidos possíveis. Vale ressaltar que nessa atividade de leitura e produção de sentidos, são mobilizadas algumas estratégias de processamento textual que se "realizam simultaneamente, vários passos interpretativos finalisticamente orientados, efetivos, eficientes, flexíveis e extremamente rápidos.” (KOCH, ELIAS, 2013, p. 39)

Essas estratégias são orientadas pela memória e por experiências individuais e coletivas que são armazenadas como conhecimentos. Koch e Elias $(2013,39-40)$ afirmam que para acessarmos o processamento textual em nossa memória "recorremos a três grandes sistemas de conhecimento: conhecimento linguístico; conhecimento enciclopédico; conhecimento interacional". Cada um, revela um conjunto de saberes específicos. O conhecimento linguístico:

Abrange o conhecimento gramatical e lexical. Baseados nesse tipo de conhecimento, podemos compreender: a organização do material linguístico na superfície textual; o uso dos meios coesivos para efetuar a remissão ou sequenciação textual; a seleção lexical adequada ao tema ou aos modelos cognitivos ativados. (KOCH, ELIAS, 2013, p. 40)

Já o conhecimento enciclopédico ou dito conhecimento de mundo: "Refere-se a conhecimentos gerais sobre o mundo - uma espécie de thesaurus mental - bem como a conhecimentos alusivos a vivências pessoais e eventos espácio-temporalmente situados, permitindo a produção de sentidos." (KOCH, ELIAS, 2013, p. 42). Vale ressaltar que nessa modalidade a característica principal parte da ideia de "ativar conhecimentos das coisas do mundo para produzir sentido a partir do linguístico materialmente constituído. (KOCH, ELIAS, 2013, p. 43).

Para Koch e Elias (2013, p. 45) o conhecimento interacional ainda engloba outros quatros conhecimentos: o ilocucional, o comunicacional, o metacomunicativo e o superestrutural. No conhecimento iloucional, as pesquisadores definem: "permite-nos reconhecer os objetivos ou propósitos pretendidos pelo produtor do texto, em uma dada situação interacional." Na mesma direção, declaram o que diz respeito ao conhecimento comunicacional:

- quantidade de informação necessária, numa situação comunicativa concreta, para que o parceiro seja capaz de reconstruir o objetivo da produção do texto;

- seleção da variante linguística adequada a cada situação de interação;

- adequação ao gênero textual à situação comunicativa. (KOCH, ELIAS, 2013, p. 50)

Assim, todo esse processo de ativação apresentado no seu passo a passo auxilia na produção de sentidos e nos permite percebe de forma didática os encaminhamentos gerados na nossa memória e experiência. Desse modo, o conhecimento metacomunicativo:

É aquele que permite ao locutor assegurar a compreensão do texto e conseguir a aceitação pelo parceiro dos objetivos com que é produzido. Para tanto, utiliza-se de vários tipos de ações linguísticas configuradas no texto por meio da introdução de sinais de articulação ou apoios textuais, atividades de formulação ou construção textual [...] $(\mathrm{KOCH}$, ELIAS, 2013, p. 52). 
Pode-se perceber a utilização de marcas textuais que chamem a atenção do leitor ou comentários sobre o próprio discurso. Já no conhecimento superestrutural ou conhecimento sobre gêneros textuais:

Permite a identificação como exemplares adequados aos diversos eventos da vida social. Envolve também conhecimentos sobre as macrocategorias ou unidades globais que distinguem vários tipos de textos, bem como sobre a ordenação ou sequenciação textual em conexão com os objetivos pretendidos. (KOCH, ELIAS, 2013, p. 54).

Toda essa separação dos conhecimentos é meramente ilustrativa e didática, sabese que no ato da leitura todos eles são ativados conjuntamente, são todos integrados e agem em unidade para a geração do sentidos dos diferentes gêneros.

\section{A literatura e as artes como proposta de leitura}

Ouso acrescentar na categoria que apresenta o conhecimento enciclopédico ou dito conhecimento de mundo; eu sugeriria um desdobramento ou acréscimo para o conhecimento literário, uma vez que, a literatura se forma por meio do movimento centrípeto e centrífugo e assim, para a apreensão dos sentidos em um texto literário, na maioria das vezes e, principalmente, nos textos da atualidade, há uma exigência para que o leitor conheça textos, prosadores e poetas específicos da literatura, sem essa singularidade a compreensão do texto fica comprometida.

\section{Antonie Compagnon declara:}

A literatura, exprimindo a exceção, oferece um conhecimento diferente do conhecimento erudito, porém mais capaz de esclarecer os comportamentos e as motivações humanas. Ela pensa, mas não como a ciência ou a filosofia. Seu pensamento é heurístico (ela jamais cessa de procurar) não algorítmico: ela procede tateando, sem cálculo, pela intuição, com faro. (2009, p. 51)

Ao tentar responder a pergunta que dá título à sua obra: Literatura para quê? Compagnon justifica:

\footnotetext{
"A verdade é que as obras-primas do romance contemporâneo dizem muito mais sobre o homem e a natureza do que graves obras de Filosofia, de História e de Crítica", assegurava Zola. Exercício de reflexão e experiência de escrita, a literatura responde a um projeto de conhecimento do homem e do mundo. Um ensaio de Montaigne, uma tragédia de Racine, um poema de Baudelaire, o romance de Proust nos ensinam mais sobre a vida do que longos tratados científicos. [...] (2009, p. 25-6)
}

Outros autores também se levantam para defender a literatura, tal como o escritor italiano Italo Calvino em Por que ler os clássicos (1993) e o pesquisador francês Vincent Jouve com a obra Por que estudar literatura? (2012) entre tantos outros. Desse modo, comprova-se a necessidade de um estudo específico que inclua a leitura de textos de literatura em sala de aula.

Calvino argumenta: 
9. Os clássicos são livros que, quanto mais pensamos conhecer por ouvir dizer, quando são lidos de fato mais se revelam novos, inesperados e inéditos.

Naturalmente isso ocorre quando um clássico "funciona" como tal, isto é, estabelece uma relação pessoal com quem o lê. Se a centelha não se dá, nada feito: os clássicos não são lidos por dever ou por respeito mas só por amor. Exceto na escola: a escola deve fazer com que você conheça bem ou mal um certo número de clássicos dentre os quais (ou em relação aos quais) você poderá depois reconhecer os "seus" clássicos. A escola é obrigada a dar-lhe instrumentos para efetuar uma opção: as escolhas que contam são aquelas que ocorrem fora e depois de casa escola. (1993, p. 12-3 - grifos do autor)

Pensando nessa perspectiva, tanto de promover a leitura específica de literatura em sala de aula, quanto no movimento de auxiliar no processo de identificação dos alunos por meio de obras que suscitem o reconhecimento de si, do outro e do mundo através da representação artística, se propõe o uso de textos literários completos e um projeto de leitura que, de fato, promova o encontro dos alunos com as obras clássicas e as locais.

Sobre o prisma do processo de reconhecimento e eventual pertencimento a um grupo social e cultural, Hall propõe:

[aos] recursos da história, da linguagem e da cultura para a produção não daquilo que nós somos, mas daquilo no qual nos tornamos. Tem a ver não tanto com as questões "quem nós somos" ou "de onde nós viemos", mas muito mais com as questões "quem nós podemos nos tornar" e "como essa representação afeta a forma de como nós podemos representar a nós próprios. (HALL, 2009, p. 109 - grifos nossos)

Sendo assim, a proposta aqui é de socializar uma experiência de trabalho realizado no nosso grupo de pesquisa, fazendo a convergência do aporte teórico da linguística textual em consonância com textos artísticos, para isso, a proposição é utilizar obras e artistas da cidade dos alunos, do estado, da região, para que eles possam desenvolver uma certa sensibilidade e um sentido de pertencimento junto ao texto artisticamente elaborado, além de ampliar os conhecimentos e estratégias de leitura e geração de sentido. Dessa forma e levando em consideração o contexto no qual o grupo se reúne e o espaço onde os trabalhos são desenvolvidos, foram selecionados dois artistas, um poeta de Cuiabá-MT (capital): Aclyse de Mattos e uma artista plástica de Sinop-MT (interior): Mari Bueno.

Aclyse de Mattos é cuiabano, estudou em São Paulo e no Rio de Janeiro e, atualmente, é professor em Cuiabá. A pesquisadora Rosana Rodrigues da Silva assim o apresenta:

O poeta expressou de modo inovado a cultura de Mato Grosso, ao compor uma obra que traduz para o campo da poesia elementos característicos da paisagem, da flora e da fauna, dos ritmos, sons e imagens que compõem a região mato-grossense. Por essa presença do olhar e do sentir cuiabanos, podemos reconhecer a temática regional que marca sua obra. Contudo, o regionalismo não limita o trabalho do poeta; sua poética revela a universalidade na forma experimental em que organiza a sintaxe, trabalha o ilhamento das palavras e dá significado aos espaços e desenhos do/no poema. (2011, p. 13) 
Escritor de várias obras como: Assalto a mão amada (1985), Quem muito olha a lua fica louco (2000), Festa (2015), entre outras. Para este trabalho foram selecionados poemas e trechos de poemas da obra Quem muito olha a lua fica louco (2000).

Um dos elementos que procura afirmar a identidade mato-grossense da obra está na citação de espaços e bairros conhecidos da capital Cuiabá, bem como seus arredores, como a Chapada dos Guimarães e o Pantanal. O recorte abaixo faz menção a um espaço bastante movimentado da capital:

Avenida Beira-Rio
e seu canteiro de flamboyants vermelhos
fila de tochas de fogo
que brotam da terra
como um cortejo, um bacanal, um enterro
um funeral de titãs do sub-mundo
( 2000, p. 30$)$

A homenagem ao Pantanal vem figurativizada no poema abaixo:

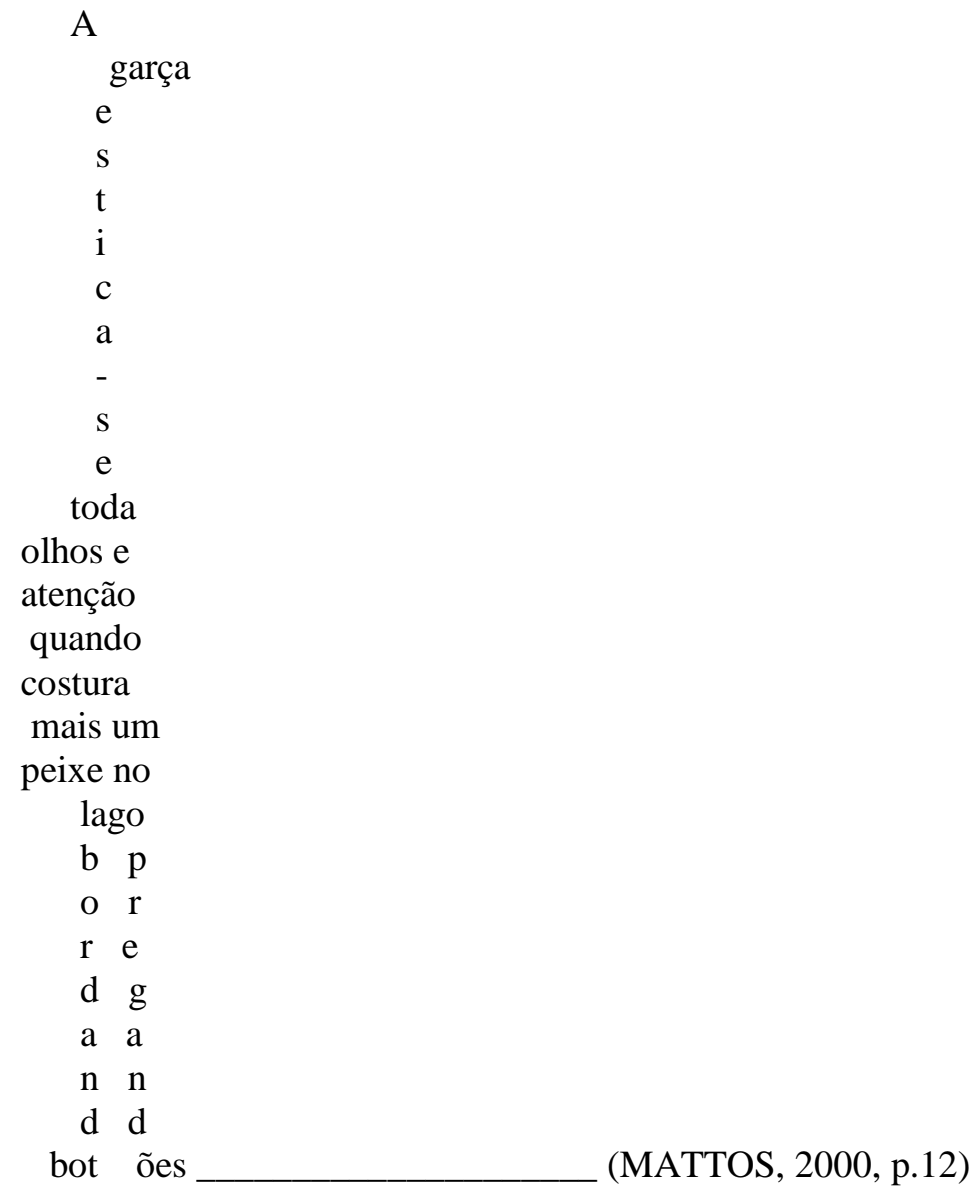

O jogo lúdico entre os espaços em branco do papel e os caracteres em preto minuciosamente escolhidos para a formação da imagem que recupera a figura do pássaro revela a capacidade de abstração, leveza e iconicidade do poeta. Nesse processo de abstração, até a experiência pessoal dialoga com o ciclo da natureza impregnada no espaço geográfico que o identifica, como se constata no trecho do poema abaixo:

"As chuvas cinzas-azuladas

do janeiro em que você nasceu

ficaram nos seus olhos 


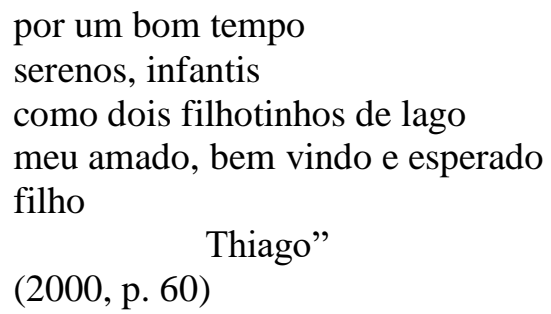

As típicas chuvas torrenciais que mudam a cor do céu de Mato Grosso em janeiro são aqui representadas no poema. Os poemas dessa a obra também fazem referências às paisagens, natureza e cultura próprias de Mato Grosso. O ciclo sazonal da região evidencia-se pela presença de duas estações: a chuva e a seca. Tal como se pode observar nos versos selecionados abaixo, em recortes feitos de diferentes poemas:

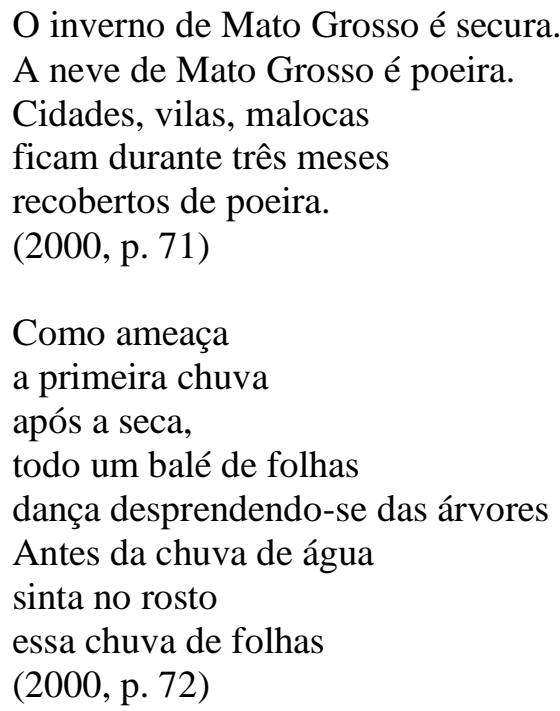

Nesses recortes notam-se a figurativização das estações que marcam a região do Mato Grosso. A seca carrega consigo a poeira e, em comparação a outros lugares, onde o inverno é sinônimo de neve e chuva, eles surgem como substitutos, evidenciando os indícios do ciclo que no estado se estabelecem. Após a seca, aparece a chuva, mas antes dela, enormes rajadas de vento as anunciam, tal como o segundo poema revela: "todo um balé de folhas" ou "antes da chuva de água / sinta no rosto / essa chuva de folhas".

A utilização desses poemas para o contexto mato-grossense proporciona uma identificação e um sentimento de pertencimento por parte dos estudantes que vivenciam essa experiência de ver e sentir uma flora, fauna, ciclo sazonal tão específicos e, muitas vezes, tão diferente aquilo que se vivencia em outras partes do país. A seleção e aplicação deste tipo de texto em sala de aula tem o propósito de promover esse reconhecimento e pode suscitar o desejo de ampliar o olhar do lugar onde se vive e até, quem sabe, suscitar no discente a intenção de escrever poeticamente sobre ele, com um olhar livre e criativo acerca do contexto vivenciado.

Na perspectiva de ampliação do olhar, sugere-se aqui o trabalho em conjunto com texto pictóricos, os quais apresentem certa convergência em relação a temática trabalha nos poemas. Para isso, apresentamos Mari Bueno é artista plástica residente da cidade de Sinop, interior de Mato Grosso. Bueno elegeu a Amazônia como cenário de suas produções; as telas da pintora foram premiadas no Egito, Estados Unidos, Alemanha, Itália, Suíça e até no Museu do Louvre, na França. O painel da Pia Batismal da Catedral Sagrado Coração de Jesus em Sinop-MT traz representados em forma de anjos: um negro, 
um branco e um indígena, já o painel Bom Pastor, há a representação de um Jesus "amazônico", moreno, em meio à vegetação típica de Mato Grosso; assumindo em espaço sagrado utilizando o multiculturalismo que identifica a sociedade contemporânea.

Para a identificação do pluralismo cultural da região do interior de Mato Grosso, foi selecionado o painel da Pia Batismal, pintado durante o ano de 2006:

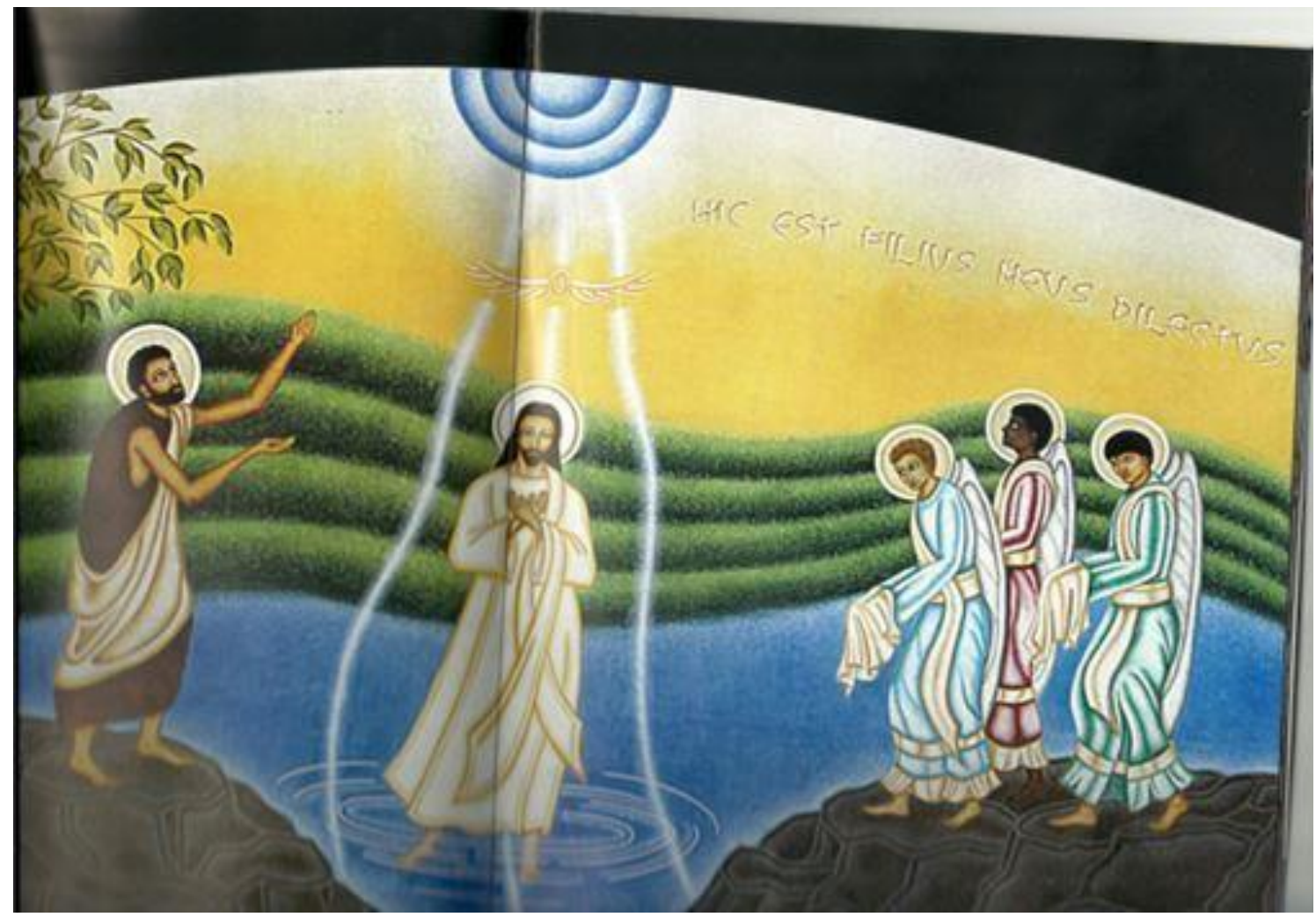

Figura 1: http://maribueno.com.br/?portfolio=sagrado-coracao

Além da representação tradicional do batismo de Cristo por João Batista, a artista inova na concepção e apresentação dos anjos que privilegiaram este momento, a artista elegeu três: um branco, um negro e um indígena, representantes de cada etnia que constitue o pluralismo cultural que formou o norte do Mato Grosso. Há ainda, uma série de simbolismos da tradição católica que se revelam nas cores selecionadas, no posicionamento de cada figura e no movimento do painel que também geram sentido ao se pensar em um espaço sacro de contemplação e transcendência.

Da série Cotidiano, foram escolhidas duas telas: 


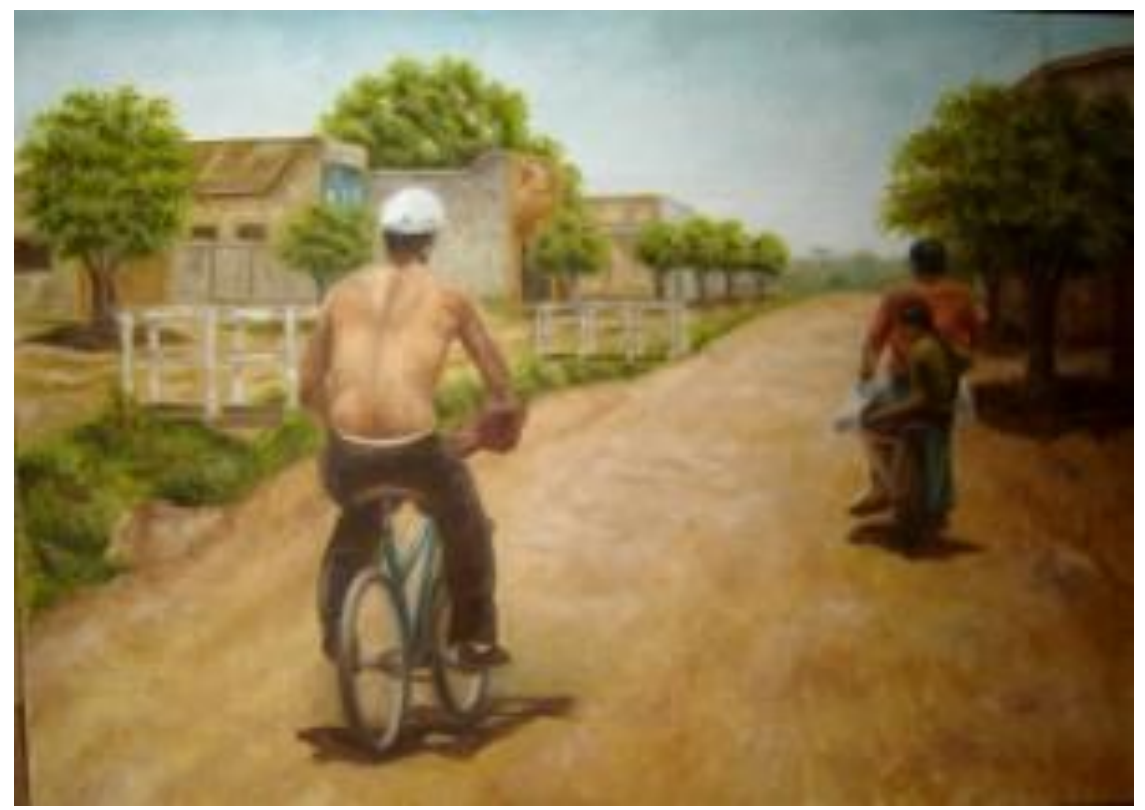

Figura 2: Fim de semana: http://maribueno.com.br/?portfolio=cotidiano

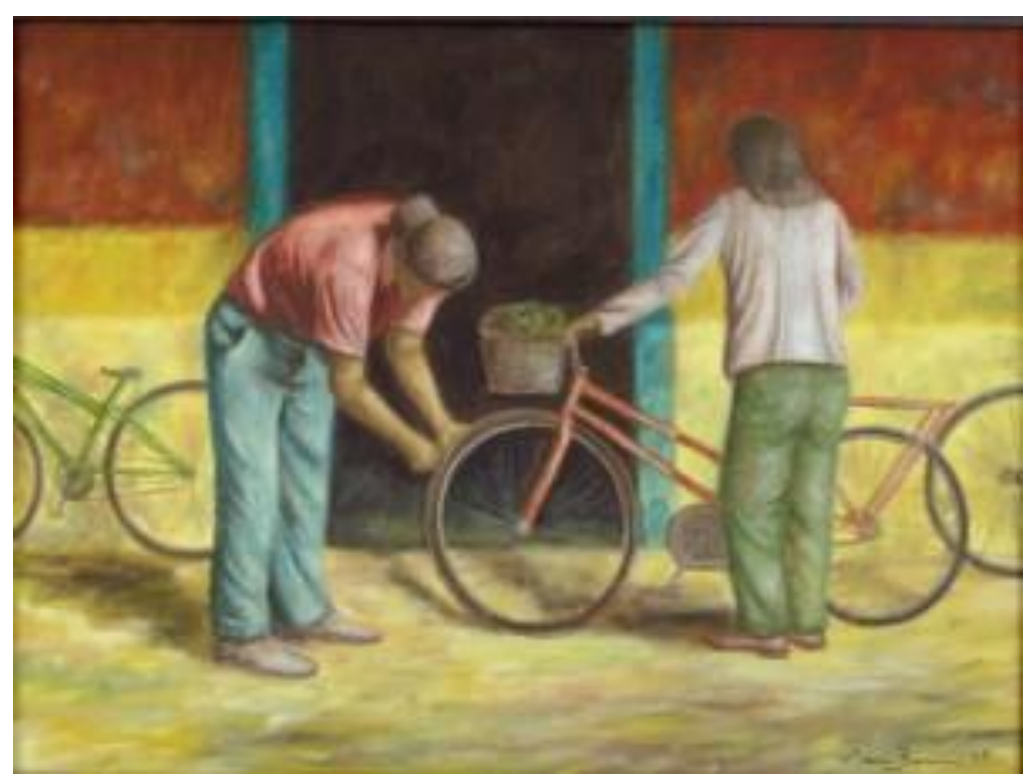

Figura 3: Oficina de bicicletas: http://maribueno.com.br/?portfolio=cotidiano

Para os moradores da cidade de Sinop, essas duas telas representam o dia a dia e a realidade de inúmeros deles. A utilização da bicicleta como meio de transporte, as ruas sem asfalto, as cores das casas, as árvores e os portões, todos eles apresentam relações de convergência com o cotidiano da cidade e revelam a realidade vivenciada por muitos moradores, alguns podem ser os alunos que observarem essas telas, podem gerar aqui, mais um vez, o sentimento de pertencimento como cidadão da cidade que o abriga.

A inserção do texto multimodal em sala de aula auxilia no desenvolvimento das capacidades leitoras dos alunos. Ressalta-se que: "O termo 'texto multimodal' tem sido usado para nomear textos constituídos por combinação de recursos de escrita (fonte, tipografia), som (palavras faladas, músicas), imagens (desenhos, fotos reais), gestos, movimentos, expressões faciais etc." (DIONISIO, VASCONCELOS, 2013, p. 21) 


\section{Considerações finais}

O diálogo entre as áreas da linguística textual com a sua gama de aportes teóricos voltados para os estudos dos gêneros textuais, para a leitura, a escrita, a geração de sentido dos textos, o processo de interação, o uso dos elementos lexicais somados ao contexto e a mobilização das estratégias que ativem os conhecimentos do leitor, bem como, a sua memória; em processo de convergência e aproximação de textos artísticos, neste caso, o poema e o texto pictórico, revela-se grandemente produtivo e profícuo. Uma vez que, sabe-se da urgência da ampliação da capacidade e habilidade leitora na formação de alunos do ensino fundamental e médio.

Há no Brasil, uma triste realidade apresentada pelos exames nacionais que mensuram a capacidade leitora da população. Os índices revelam resultados de baixíssimo empenho em relação a países com desenvolvimento inferior ao Brasil. A escola é a principal agência formadora dos processos de letramento e alfabetização e precisa considerar esses índices e propor inovações para promover a alteração positiva desses resultados.

Observa-se o uso de vários gêneros textuais em sala de aula. As formações promovidas pelo estado e município já conseguiram ampliar o leque de escolhas de diferentes gêneros a serem trabalhados em sala de aula. Contudo, é gritante a ausência de gêneros da literatura e textos artísticos, há uma exclusão silenciosa que lesa a ampliação das habilidades de leitura dos alunos. Vale salientar que a linguagem constitui um fator de identidade para um grupo social e a utilização de textos que suscitem essa identificação e aprofunde a ampliação das habilidades leitora, pode auxiliar na busca de resultados mais positivos em cada comunidade do nosso país.

Neste trabalho, foi apresentada uma proposta que vai nesse sentido de convergência e diálogo entre as áreas da linguística textual e da teoria da literatura. $\mathrm{O}$ aproveitamento de textos artísticos produzidos na localidade do aluno, seja o poema, seja a pintura, facilitam tanto a ampliação da habilidade leitora quanto a noção de pertencimento e desenvolvimento do processo de identidade individual e coletiva, tal como foi o resultado positivo da aplicação dessa atividade realizada pelo projeto de pesquisa aqui apresentado.

\section{Referências Bibliográficas}

CALVINO, Italo. Por que ler os clássicos. Tradução de Nilson Moulin. São Paulo: Companhia das Letras, 1993.

CAVALCANTE, M. M. "Texto, contexto e coerência." In: Os sentidos do texto. São Paulo: Contexto, 2013.

COMPAGNON, Antonie. Literatura para quêe? Tradução de Laura Taddei Brandini. Belo Horizonte: Editora UFMG, 2009. 
DIONISIO, A. P. VASCONCELOS, L. J. "Multimodalidade, gênero textual e leitura". In: BUNZEN, C. MENDONÇA, M. Múltiplas linguagens para o ensino médio. São Paulo: Parábola Editorial, 2013.

HALL, Stuart. A identidade cultural na pós-modernidade. Rio de Janeiro: DP\&A, 2006.

MATTOS, A. Quem muito olha a lua fica louco. Cuiabá: Oficina Mínima, 2000.

KOCH, I. V. "Introdução". IN: Introdução à linguística textual: trajetória e grande temas. São Paulo: WMF Martins Fontes, 2009.

KOCH, I.V. ELIAS, V. M. Ler e compreender os sentidos do texto. São Paulo: Contexto, 2013.

SCARPELLI, M. F. "Heterogeneidade, transculturação, hibridismo: a terceira margem da cultura latino-americana." In: CHAVES, R. MACÊDO, T. (Org.) Literaturas em movimento: hibridismo cultural e exercício crítico. São Paulo: Arte \& Ciência, 2003. SILVA, Tomaz Tadeu da (org.). Identidade e diferença: a perspectiva dos estudos culturais. Rio de Janeiro: Vozes, 2009.

SILVA, Rosana Rodrigues. COCCO, Marta Helena. (Org.) Nossas vozes, nossa chão: antologia poética comentada. Cuiabá: Carlini \& Caniato, 2011. 